\title{
Aspirin Treatment Increases the Risk of Cerebral Microbleeds
}

\author{
Lihong Ge, Guangming Niu, Xiaodong Han, Yang Gao, Qiong Wu, Hui Wu, \\ Ying Zhang, Dongling Guo
}

\begin{abstract}
Background: The objective of the study was to determine the frequency of cerebral microbleeds (CMBs) by using phasesensitive imaging in patients with previous transient ischemic attack (TIA) or stroke who were receiving aspirin treatment. Methods: We retrospectively analyzed 300 outpatients with ischemic cerebrovascular disease: 150 had been receiving aspirin treatment for $>1$ year (patients), and 150 controls had not previously received aspirin. Cerebral microbleeds were defined by a trained observer (blinded to clinical details) according to results of T2-weighted, T1-weighted, diffusion-weighted, and phase-sensitive magnetic resonance imaging (MRI). Numerous vascular risk factors including white matter hyperintensity (WMH), duration of aspirin treatment, age, hypertension or diabetes mellitus were investigated for a possible association with the presence of CMBs in the two groups. Results: The frequency of CMBs $(60 / 150(40 \%)$ vs $18 / 150$ (12\%); odds ratio 4.899, p <0.0001) and intracerebral hemorrhage (ICH) $(42 / 150(28 \%)$ vs $2 / 150$ $(1 \%)$; odds ratio $28.778, \mathrm{p}<0.0001)$ were significantly higher in the patients than in the controls. Among patients, those using aspirin for $>5$ years $(42 / 68(62 \%)$ showed a higher frequency of CMBs than those receiving aspirin for $\leq 5$ years(18/82 (22\%); odds ratio 5.744 , $\mathrm{p}<0.0001)$. WMH $(\mathrm{p}=0.020 / 0.030,0.007 / 0.000)$ age $(\mathrm{p}=0.007 / 0.000)$ and hypertension $(\mathrm{p}=0.000 / 0.033)$, in patients and controls respectively, were each associated with CMBs. Conclusions: There was a clear impact of aspirin treatment on CMBs associated with intracerebral hemorrhage in Chinese patients. The frequency of CMBs and hemorrhagic complications was higher in patients treated with long-term aspirin.
\end{abstract}

RÉSUMÉ: Le traitement par l'aspirine augmente le risque de micro saignements cérébraux. Contexte : L'objectif de l'étude était de déterminer la fréquence de micro saignements cérébraux (MSC) au moyen de l'imagerie par contraste de phase chez les patients qui recevaient de l'aspirine suite à des accès ischémiques transitoires cérébraux (ITC) ou à un accident vasculaire cérébral. Méthode : Nous avons analysé rétrospectivement les dossiers de 300 patients externes atteints d'une maladie cérébrovasculaire ischémique : 150 recevaient de l'aspirine depuis plus d'un an (les patients) et 150 témoins ne recevaient pas d'aspirine. Les MSC étaient identifiés par un observateur entraîné (à l'aveugle quant aux données cliniques) selon les résultats de l'IRM pondérée en T2, T1, diffusion et contraste de phase. Nous avons examiné s'il existait une association entre la présence de MSC dans les deux groupes et plusieurs facteurs de risque vasculaire dont l'hyperintensité de la substance blanche (HSB), la durée du traitement par l'aspirine, l'âge, l'hypertension et le diabète. Résultats : La fréquence des MSC, soit 60/150 (40\%) contre 18/150 (12\%) [rapport de cotes (RC) 4,899; p < 0,0001] et la fréquence des HIC, soit 42/150 patients (28\%) contre 2/150 (1\%) (RC 28,778; p < 0,0001) étaient significativement plus élevées chez les patients que chez les témoins. Parmi les patients, ceux qui prenaient de l'aspirine depuis plus de 5 ans, soit $42 / 68$ (62\%) avaient une fréquence plus élevée de MSC que ceux qui recevaient de l'aspirine depuis 5 ans ou moins, soit 18/82 (22\%) (RC 5,744; p < 0,0001). La présence d'HSB (p = 0,020/0,030; $0,007 / 0,000)$ l'âge $(\mathrm{p}=0,007 / 0,000)$ et l'hypertension ( $\mathrm{p}=0,000 / 0,033)$ chez les patients et les témoins respectivement étaient associés aux MSC. Conclusions : Le traitement par l'aspirine avait un impact significatif sur les MSC associées à l'hémorragie intracérébrale chez les patients chinois. La fréquence des MSC et des complications hémorragiques étaient plus élevées chez les patients qui prenaient de l'aspirine à long terme.

Can. J. Neurol. Sci. 2011; 38: 863-868

Antiplatelet agents, especially aspirin, are effective for the prevention of secondary stroke and cardiovascular diseases, and have been widely used in most patients in China. Long-term antiplatelet therapy reduces the risk of recurrent stroke, myocardial infarction, and vascular death in patients with stroke or ischemic heart disease, but it may be associated with increased risk of intracerebral hemorrhage (ICH), ${ }^{1-4}$ which is an uncommon but often fatal or disabling treatment complication. Identification of risk factors will therefore help to prevent $\mathrm{ICH}$ in patients receiving aspirin, especially in long-term users.

Cerebral microbleeds (CMBs) are considered to be indicative of bleeding-prone microangiopathy and ICH. They appear as round hypointense regions on $\mathrm{T} 2 *$-weighted magnetic resonance imaging (MRI) ${ }^{5,6}$ Cerebral microbleeds may indicate advancedstage cerebral microangiopathy and are detected in around $60 \%$ of patients with primary ICH. ${ }^{7,8}$ Some investigations suggest that the frequency of CMBs increases if patients are treated with

From the Department of Imaging (LG, GN), Beijing Tiantan Hospital Affiliated to Capital Medical University, Beijing; Department of Magnetic Resonance (GN, XH, YG, QW, HW, YZ, DG), The Affiliated Hospital of Inner Mongolia Medical College, Hohhot, China.

Received March 2, 2011. Final Revisions Submitted July 4, 2011. Correspondence to: Guangming Niu, Department of Imaging, Beijing Tiantan Hospital Affiliated to Capital Medical University, Beijing, 100050, China. 
antithrombotic drugs, ${ }^{9-13}$ while other studies suggest that antithrombotic drug treatment has no effect on the frequency of CMBs. ${ }^{14-16}$ The significance of microbleeds in patients receiving antiplatelet therapy therefore remains controversial, and the impact of long term regular use of aspirin in patients with potential ischemic disease remains unclear.

In this study we used phase-sensitive imaging ${ }^{17}$ to determine whether the frequency of CMBs is associated with aspirin therapy in patients with ischemic cerebrovascular disease.

\section{METHODS}

The study included 300 patients with ischemic cerebrovascular disease, either stroke or transient ischemic attack (TIA). The stroke patients had previously received either aspirin or traditional Chinese medicine and the TIA patients had previously received aspirin or no therapy. Two groups of patients were selected for the study. The initial group to be selected were 150 consecutive patients who had been receiving aspirin treatment for $>1$ year. A control group of 150 patients who had not received aspirin were then randomly selected. Clinical factors associated with increased CMB risk, including sex, age and severe hypertension, were matched in the patients and the control groups. None of the patients in the study had previously received anticoagulant or thrombolytic therapy. For inclusion into the study patients were required to have a diastolic blood pressure between 90 and $140 \mathrm{~mm} \mathrm{Hg}$ and a systolic blood pressure between 140 and $180 \mathrm{~mm} \mathrm{Hg}$.

All patients were fully informed about the nature and objectives of the study. The study was approved by the institutional health service, and informed written consent was obtained from either the patients or their caregivers.

Magnetic resonance imaging examinations of the brain were performed on a 3.0-Tesla MR scanner (Signa HDx GE Healthcare, USA). All patients underwent an MRI series comprising T1-weighted fluid-attenuated inversion recovery (FLAIR) imaging (repetition time, $1976 \mathrm{~ms}$; echo time, $25.2 \mathrm{~ms}$; inversion time, $860.0 \mathrm{~ms}$; section thickness, $5 \mathrm{~mm}$; field of view, $24 \times 18 \mathrm{~cm}$; matrix, $320 \times 224$; NEX, 1.0). In addition, T2weighted fast spin-echo/propeller imaging (repetition time, 4700 $\mathrm{ms}$; echo time, $114.0 \mathrm{~ms}$; section thickness, $5 \mathrm{~mm}$; field of view, $24 \times 24 \mathrm{~cm}$; matrix, $320 \times 320$; NEX, 1.0); and diffusionweighted imaging $(b=1000$; repetition time, $4450 \mathrm{~ms}$; echo time, $76.6 \mathrm{~ms}$; section thickness, $5 \mathrm{~mm}$; field of view, $24 \times 24$ $\mathrm{cm}$; matrix, $128 \times 128$; NEX, 2.0) were performed. An enhanced T2*-weighted angiography (ESWAN) scan was obtained using a repetition time/echo time, 53.3/5.1 ms; flip angle, $20^{\circ}$; field of view, $24 \times 24$; slice thickness, 1.8 ; slice spacing, $0 \mathrm{~mm}$; matrix, $448 \times 352$. The phase-sensitive images obtained with ESWAN were processed using the GE ESWAN Functool software, which was a part of the Advantage Workstation 4.3.

Cerebral microbleeds were identified by a low signal in the T2 *-weighted MRI and cannot be demonstrated by conventional MRI or CT scans.

The MRI images were independently evaluated by two of the authors (Q Wu and $\mathrm{H} \mathrm{Wu}$ ) who were blinded to the patients' clinical profiles. The number of microbleeds and the grading scores for white matter hyperintensity (WMH) were determined by consensus. Lesions within the sulcal areas likely to represent adjacent pial blood vessels and areas of symmetrical hypodensity in the globus pallidus, which were likely to indicate calcification, were excluded. The severity of CMBs was classified by using a four point scoring system according to Lee et al, ${ }^{18}$ where: absent, mild $=1-5$, moderate $=5-10$, and severe $>10$. The severity of a WMH on T2-weighted images was classified as 'punctuate', 'early confluent', or 'confluent' by previously described methods. ${ }^{19}$

The presence of vascular risk factors, including controlled hypertension, diabetes mellitus or hyperlipidemia was evaluated according to the method described by Orken et $\mathrm{al}^{14}$. Hypertension was considered to be present when a patient had received antihypertensive treatment before admission or when hypertension was diagnosed during a hospital stay evidenced by systolic and diastolic blood pressures of at least 140 and $90 \mathrm{~mm}$ $\mathrm{Hg}$ on multiple occasions. Diabetes mellitus (DM) was defined as a history of DM with or without current hypoglycemic treatment, or by the demonstration of two fasting plasma glucose levels of $126 \mathrm{mg} / \mathrm{dL}$ or higher. A diagnosis of hyperlipidemia was based on a fasting serum total cholesterol level $>220 \mathrm{mg} / \mathrm{dL}$, or was considered to be present in patients currently undergoing cholesterol-lowering therapy. A history of smoking was noted when a subject was either a current smoker or an ex-smoker who had quit smoking less than five years before admission. Addiction to alcohol was considered as a risk factor if current consumption reached $300 \mathrm{~g} /$ week.

Statistical analysis was undertaken using the Statistical Package for the Social Sciences for Windows version 16.0 (SPSS, Chicago, Illinois). Age, expressed as mean \pm standard deviation (SD), was analyzed using the unpaired Student t-test between the patients and controls. Chi-square or the Fisher exact tests were used to compare clinical variables between patients who had CMBs and those who did not, and between patients who received aspirin treatment and those who did not. Multivariate logistic regression analysis was performed to identify potential risk factors and associations between cerebral microbleeds and clinical characteristics. Statistical significance was established by using a conventional $\mathrm{p}<0.05$ level.

\section{RESULTS}

Demographic and disease characteristics for the 300 cases are summarized in Table 1. No significant differences were found in age, sex ratio, hypertension, cardiac diseases, diabetes mellitus, hyperlipidemia, smoking, alcohol addiction, or previous stroke between the aspirin treatmed patients and the controls, suggesting that the two groups were well matched for all clinical characteristics and potential confounding factors. Mean \pm SD blood pressure was $109.6 \pm 10.2 / 70.1 \pm 6.9 \mathrm{mmHg}$ in the patients and $110 \pm 9.0 / 68.8 \pm 5.3 \mathrm{~mm} \mathrm{Hg}$ in the controls. Blood pressure in the hypertensive patients was $142.65 \pm 14.7 / 89.55 \pm 9.08 \mathrm{~mm} \mathrm{Hg}$. Table 2 shows that the frequency of CMBs was significantly higher in the patients $(60 / 150 ; 40 \%$ than in the controls $(18 / 150$; $12 \%$; odds ratio $4.899, \mathrm{p}<0.0001)$. The frequency of intracerebral bleeding (resolved hematoma, acute or subacute hematoma) was $42 / 150(28 \%)$ in patients and $2 / 150(1 \%)$ in controls (odds ratio 28.778, $\mathrm{p}<0.0001$; Table 2).

In total, there were 27 cases of ICH in patients with CMBs, but only one case in the controls with CMBs (Tables 3 and 4). As shown in Table 3, the frequency of hemorrhagic complications was higher in patients with CMBs $(27 / 60 ; 45 \%)$ 
Table 1: Characteristics of patients and controls

\begin{tabular}{lccc}
\hline & $\begin{array}{c}\text { Patients } \\
(\mathbf{n}=\mathbf{1 5 0})\end{array}$ & $\begin{array}{c}\text { Controls } \\
(\mathbf{n}=\mathbf{1 5 0})\end{array}$ & P value* \\
\hline Age (years) & $65.88 \pm 8.99$ & $64.38 \pm 7.47$ & 0.147 \\
Male & $87(58 \%)$ & $83(55 \%)$ & 0.641 \\
Hypertension & $88(59 \%)$ & $81(54 \%)$ & 0.415 \\
Cardiac diseases & $59(39 \%)$ & $63(42 \%)$ & 0.638 \\
Diabetes & $34(23 \%)$ & $29(19 \%)$ & 0.478 \\
Hypercholesterolemia & $67(45 \%)$ & $61(41 \%)$ & 0.484 \\
Smoking & $68(45 \%)$ & $60(40 \%)$ & 0.350 \\
Alcohol & $72(48 \%)$ & $62(41 \%)$ & 0.246 \\
Previous stroke & $48(32 \%)$ & $52(35 \%)$ & 0.624 \\
WMH & $83(55 \%)$ & $76(51 \%)$ & 0.418 \\
CMBs & $60(40 \%)$ & $18(12 \%)$ & $<0.0001$ \\
ICH & $42(28 \%)$ & $2(1 \%)$ & $<0.0001$ \\
\hline
\end{tabular}

* $\mathrm{t}$ test for age; chi square, Fisher exact test for other variables

than in patients without CMBs $(15 / 90 ; 17 \%)$. The frequency of each of the moderate and severe grades of CMBs was also lower in controls than in patients but the differences were not statistically significant (Table 2).

Imaging analysis showed that the frequency of $\mathrm{WMH}$ was associated with the presence of CMBs (45/60 (75\%) vs 43/90 $(48 \%)$; odds ratio $3.279, \mathrm{p}=0.001$ ) in the patients (Table 3$)$, and there was a trend towards an association in the controls $(\mathrm{p}=0.81)$ (Table 4).
Multivariate logistic regression analyses indicated that the frequencies of CMBs were associated with the frequency of $\mathrm{WMH}$ in the patients (odds ratio 3.329, $\mathrm{p}=0.020$ ) and controls (odds ratio 3.988, $\mathrm{p}=0.030$,) (Table 5). Multivariate logistic regression analysis also suggested that the frequencies of CMBs were significantly associated with the frequency of age $(>70$ years), and hypertension in the two groups (Table 5). Notably, the risk of $\mathrm{CMBs}$ in long term aspirin treatment ( $>5$ years)

Table 2: Analysis for the presence of CMBs and bleeding between the patients and the controls

\begin{tabular}{lcccc}
\hline & $\begin{array}{c}\text { Patients } \\
(\mathbf{n = 1 5 0 )}\end{array}$ & $\begin{array}{c}\text { Controls } \\
(\mathbf{n = 1 5 0 )}\end{array}$ & $\begin{array}{c}\text { Odds Ratio } \\
(\mathbf{9 5 \%} \text { CI) }\end{array}$ & P value* $^{*}$ \\
\hline CMBs & $60(40 \%)$ & $18(12 \%)$ & $4.889(2.707-8.802)$ & $<0.0001$ \\
Mild (1-5) & $14(23 \%)$ & $10(56 \%)$ & $0.243(0.181-0.736)$ & 0.009 \\
Moderate (5-10) & $34(57 \%)$ & $6(33 \%)$ & $2.615(0.866-7.897)$ & 0.082 \\
Severe $(>10)$ & $12(20 \%)$ & $2(11 \%)$ & $2.000(0.404-9.909)$ & 0.609 \\
ICH & $42(28 \%)$ & $2(1 \%)$ & $28.778(6.818-121.467)$ & $<0.0001$ \\
\hline
\end{tabular}

* Chi square, Fisher exact test

Table 3: Association of CMB with WMH and ICH in patients

\begin{tabular}{lcccc}
\hline & $\begin{array}{c}\text { CMBs(+) } \\
(\mathbf{n = 6 0})\end{array}$ & $\begin{array}{c}\text { CMBs(-) } \\
(\mathbf{n = 9 0 )}\end{array}$ & $\begin{array}{c}\text { Odds Ratio } \\
(\mathbf{9 5 \%} \text { CI) }\end{array}$ & P value* $^{*}$ \\
\hline WMH & $45(75 \%)$ & $43(48 \%)$ & $3.279(1.603-6.709)$ & 0.001 \\
Punctuate & $15(33 \%)$ & $24(56 \%)$ & $0.971(0.434-1.937)$ & 0.820 \\
Early confluent & $21(47 \%)$ & $18(42 \%)$ & $2.154(1.027-4.516)$ & 0.040 \\
Large confluent & $9(20 \%)$ & $1(2 \%)$ & $15.706(1.934-127.549)$ & 0.001 \\
ICH & $27(45 \%)$ & $15(17 \%)$ & $4.091(1.928-8.681)$ & $<0.0001$ \\
\hline
\end{tabular}

* Chi square, Fisher exact test 
Table 4: Association of CMB with WMH and bleeding in the controls

\begin{tabular}{lcccc}
\hline & $\begin{array}{c}\text { CMBs(+) } \\
(\mathbf{n = 1 8})\end{array}$ & $\begin{array}{c}\text { CMBs(-) } \\
(\mathbf{n = 1 3 2})\end{array}$ & $\begin{array}{c}\text { OddsRatio } \\
(\mathbf{9 5 \%} \text { CI) }\end{array}$ & P value* \\
\hline WMH & $13(72 \%)$ & $65(49 \%)$ & $2.680(0.904-7.942)$ & 0.081 \\
Punctuate & $6(46 \%)$ & $30(46 \%)$ & $1.000(0.303-3.302)$ & 1.000 \\
Early confluent & $6(46 \%)$ & $31(48 \%)$ & $0.940(0.285-3.103)$ & 0.919 \\
& & & & $1.271(0.130-12.388)$ \\
Large confluent & $1(20 \%)$ & $4(6 \%)$ & & 1.000 \\
& & & $7.706(0.460-128.955)$ & 0.226 \\
\hline
\end{tabular}

* Chi square, Fisher exact test

$(42 / 68 ; 62 \%)$ was higher than that in short term aspirin treatment ( $\leq 5$ years) $(18 / 82 ; 22 \%$, odds ratio $5.744, \mathrm{p}<0.0001$; Table 6$)$. The risk of $\mathrm{ICH}$ was numerically higher in patients receiving long term $(25 \%)$ than in those receiving shorter-term aspirin treatment $(12 \% ; \mathrm{p}=0.87$ ) (Table 6).

\section{Discussion}

The present study demonstrated that the presence of CMBs was associated with the use of the antiplatelet drug aspirin. Various studies have suggested that CMBs might be indicative of bleeding tendency and bleeding transformation after acute ischemic stroke. The present study supports this association showing a higher frequency of hemorrhagic complications in patients with $\mathrm{CMBs}$ than in patients without $\mathrm{CMBs}$ (Table3, $\mathrm{p}<0.0001$ ).

The frequency of CMBs has previously been linked to age, sex, history of cerebrovascular diseases, hypertension and diabetes mellitus. ${ }^{9-16,20-22}$ It has also been established that bleeding complications are common adverse events of aspirin when used to prevent ischemic stroke arising from recurrent cerebral embolism. Overuse of antiplatelet therapy by itself may increase the risk of $\mathrm{ICH}$, whereas ischemic events treated with

Table 5: Multivariate logistic regression analysis for the associated factors with CMBs in the patients/controls

\begin{tabular}{|c|c|c|c|}
\hline & $\begin{array}{c}\text { Odds Ratio } \\
\text { (patients/controls) }\end{array}$ & $\begin{array}{c}\text { 95\% CI for Odds Ratio } \\
\text { (patients/controls) }\end{array}$ & $\begin{array}{c}\text { P value* } \\
\text { (patients/controls) }\end{array}$ \\
\hline WMH & $3.329 / 3.988$ & $1.206-9.195 / 1.144-13.902$ & $0.020 / 0.030$ \\
\hline Age ( $>70$ years) & $3.650 / 3.790$ & $1.437-9.276 / 1.783-6.769$ & $0.007 /<0.0001$ \\
\hline Hypertension & $11.899 / 3.973$ & $3.888-36.418 / 1.115-14.157$ & $<0.0001 / 0.033$ \\
\hline Smoking & $2.248 / 0.940$ & $0.737-6.859 / 0.186-4.749$ & $0.155 / 0.940$ \\
\hline Cardiac diseases & $0.891 / 0.336$ & $0.362-2.196 / 0.101-10.120$ & $0.802 / 0.076$ \\
\hline Diabetes & $0.988 / 0.806$ & $0.373-2.621 / 0.190-3.425$ & $0.981 / 0.771$ \\
\hline Previous Stroke & $0.795 / 0.434$ & $0.376-2.398 / 0.986-9.896$ & $0.798 / 0.084$ \\
\hline
\end{tabular}

* Multivariate analysis 


\section{Table 6: Analysis for the association between CMBs and ICH with the duration of} aspirin treatment in the patients

\begin{tabular}{lcccc}
\hline & $\begin{array}{c}\leq \mathbf{5 y e a r s} \\
\mathbf{( n = 8 2 )}\end{array}$ & $\begin{array}{c}>\text { 5years } \\
\mathbf{( n = 6 8 )}\end{array}$ & $\begin{array}{c}\text { Odds Ratio } \\
(\mathbf{9 5 \%} \mathbf{C I})\end{array}$ & P value* \\
\hline CMBs & $18(30 \%)$ & $42(70 \%)$ & $5.744(2.807-11.753)$ & $<0.0001$ \\
& & & $1.070(0.466-2.460)$ & 0.873 \\
\hline
\end{tabular}

* Chi square, Fisher exact test

the use of aspirin may have predisposed patients to microbleeds. Both are important clinical issues in primary and secondary stroke prevention.

The mechanisms underlying CMBs remains unclear, but there is a probable link with $\mathrm{ICH}$. In our study CMBs seen on gradient echo MRI were histopathologically correlated with extravasation of blood and microangiopathy. ${ }^{6}$ Nighoghossian et $\mathrm{al}^{23}$ demonstrated an increased occurrence of cerebral bleeding in patients with CMBs and suggested that the associated vascular vulnerability contributes to hemorrhagic transformation. Naidech et al reported an association between reduced platelet activity induced by aspirin, intraventricular hemorrhage and death after $\mathrm{ICH} .{ }^{24}$ They also found that aspirin was associated with increased ICH volume and a worse functional outcome. ${ }^{20}$ By contrast a previously reported retrospective analysis of 106 patient with ICH found no evidence to suggest that regular use of aspirin was associated with CMBs. ${ }^{16}$

In our study, we found that the frequencies of CMBs were significantly associated with the presence of WMH, age $(>70$ years) and hypertension in patients with or without antiplatelet treatment. Notably, the frequency of bleeding complications was higher in the patients than in the controls (Table $1, \mathrm{p}<0.0001$ ), suggesting that antiplatelet treatment increases the risk of bleeding. More importantly, we found that the risk of CMBs in long term aspirin treatment ( $>5$ years) was higher than that in short term aspirin treatment (Table 6), and that patients with CMBs were older and had more hypertension and more WMH than the patients without CMBs. The presence of large confluent WHM was more prevalent in patients than in controls (Table 3), providing speculative evidence that WMH may cause CMBs and that aspirin may increase their incidence (Table 2).

Our study also suggests that the presence of $\mathrm{CMBs}$ is not associated with previous stroke, cerebral infarction, or with diabetes (Table 5). The limitations of small sample size and short duration of follow-up in the present study prevent us from concluding definitively that there is a higher incidence of CMBs and ICH during long-term antiplatelet therapy with aspirin. However, the study shows that there are no statistically significant differences in the frequency of ICH between patients who received long-term aspirin and those requiring short term aspirin treatment (Table 6). However, the presence of macroscopic hematoma, which was often present in patients with $\mathrm{ICH}$, tended to make it more likely that microbleeds would be identified by MRI and so added bias to the evaluation. An additional limitation to our study was the cross-sectional design which meant that it was not possible to conclude that CMBs were solely related to aspirin treatment. Selection bias was also an issue with previous retrospective studies of this type. ${ }^{16}$

With these limitations in mind, the results of the present study do clearly suggest an impact of aspirin treatment on the rate of CMBs associated with ICH. Screening for CMBs before the initiation of long-term antiplatelet therapy may help reduce the incidence of drug-related cerebral hemorrhage. In addition, aspirin should be prescribed with caution, particularly, in patients with microbleeds at many sites.

\section{REFERENCES}

1. Baigent C, Blackwell L, Collins R, et al. Aspirin in the primary and secondary prevention of vascular disease: collaborative metaanalysis of individual participant data from randomised trials. Lancet. 2009;373(9678):1849-60.

2. Gorelick PB, Weisman SM. Risk of hemorrhagic stroke with aspirin use: an update. Stroke. 2005;36(8):1801-7.

3. Boysen G. Bleeding complications in secondary stroke prevention by antiplatelet therapy: a benefit-risk analysis. J Intern Med. 1999;246(3):239-45

4. Naidech AM, Bendok BR, Garg RK, et al. Reduced platelet activity is associated with more intraventricular hemorrhage. Neurosurgery. 2009;65(4):684-88; discussion 688.

5. Offenbacher H, Fazekas F, Schmidt R, et al. MR of cerebral abnormalities concomitant with primary intracerebral hematomas. AJNR Am J Neuroradiol. 1996;17(3):573-8.

6. Fazekas F, Kleinert R, Roob G, et al. Histopathologic analysis of foci of signal loss on gradient-echo T2*-weighted MR images in patients with spontaneous intracerebral hemorrhage: evidence of microangiopathy-related microbleeds. AJNR Am J Neuroradiol. 1999;20(4):637-42.

7. Han J, Gao P, Lin Y, et al. Three-tesla magnetic resonance imaging study of cerebral microbleeds in patients with ischemic stroke. Neurol Res. 2009;31(9):900-3.

8. Roob G, Lechner A, Schmidt R, et al. Frequency and location of microbleeds in patients with primary intracerebral hemorrhage. Stroke. 2000;31(11):2665-9.

9. Lovelock CE, Cordonnier C, Naka H, et al. Antithrombotic drug use, cerebral microbleeds, and intracerebral hemorrhage: a systematic review of published and unpublished studies. Stroke. 2010;41(6):1222-8.

10. Vernooij MW, Haag MD, van der Lugt A, et al. Use of antithrombotic drugs and the presence of cerebral microbleeds: the Rotterdam Scan Study. Arch Neurol. 2009;66(6):714-20.

11. Leys D, Cordonnier C. Brain microbleeds as a potential risk factor for antiplatelet-related intracerebral haemorrhage. J Neurol Neurosurg Psychiatry. 2010;81(6):589-90.

12. Gregoire SM, Jager HR, Yousry TA, et al. Brain microbleeds as a potential risk factor for antiplatelet-related intracerebral haemorrhage: hospital-based, case-control study. J Neurol Neurosurg Psychiatry. 2010;81(6):679-84. 
13. Soo YO, Yang SR, Lam WW, et al. Risk vs benefit of antithrombotic therapy in ischaemic stroke patients with cerebral microbleeds. J Neurol. 2008;255(11):1679-86.

14. Orken DN, Kenangil G, Uysal E, et al. Cerebral microbleeds in ischemic stroke patients on warfarin treatment. Stroke. 2009;40 (11):3638-40

15. Ueno $H$, Naka H, Ohshita T, et al. Association between cerebral microbleeds on $\mathrm{T} 2 *$-weighted $\mathrm{MR}$ images and recurrent hemorrhagic stroke in patients treated with warfarin following ischemic stroke. AJNR Am J Neuroradiol. 2008;29(8):1483-6.

16. Nishikawa T, Ueba T, Kajiwara M, et al. Cerebral microbleeds in patients with intracerebral hemorrhage are associated with previous cerebrovascular diseases and white matter hyperintensity, but not with regular use of antiplatelet agents. Neurol Med Chir (Tokyo). 2009;49(8):333-9; discussion 338-9.

17. Nandigam RN, Viswanathan A, Delgado P, et al. MR imaging detection of cerebral microbleeds: effect of susceptibilityweighted imaging, section thickness, and field strength. AJNR Am J Neuroradiol. 2009;30(2):338-43.

18. Lee SH, Bae HJ, Yoon BW, et al. Low concentration of serum total cholesterol is associated with multifocal signal loss lesions on gradient-echo magnetic resonance imaging: analysis of risk factors for multifocal signal loss lesions. Stroke. 2002;33(12): 2845-9.
19. Fazekas F, Chawluk JB, Alavi A, et al. MR signal abnormalities at 1.5 $\mathrm{T}$ in Alzheimer's dementia and normal aging. AJR Am J Roentgenol. 1987;149(2):351-6.

20. Naidech AM, Jovanovic B, Liebling S, et al. Reduced platelet activity is associated with early clot growth and worse 3-month outcome after intracerebral hemorrhage. Stroke. 2009;40(7): 2398-401.

21. Roob G, Schmidt R, Kapeller P, et al. MRI evidence of past cerebral microbleeds in a healthy elderly population. Neurology. 1999;52 (5):991-4

22. Liu PF, Cui YZ, Na J, Gao PY. Cerebral microbleeds - prevalence, distribution and risk factors in northeast population without preceding large-area stroke. Chin Med J (Engl). 2010;123: 286-90.

23. Nighoghossian N, Hermier M, Adeleine P, et al. Old microbleeds are a potential risk factor for cerebral bleeding after ischemic stroke: a gradient-echo T2*-weighted brain MRI study. Stroke. 2002; 33(3):735-42.

24. Naidech AM, Bernstein RA, Levasseur K, et al. Platelet activity and outcome after intracerebral hemorrhage. Ann Neurol. 2009;65 (3):352-6. 